\title{
Cumulative effects of infrastructure and human disturbance: a case study with reindeer
}

\author{
Sindre Eftestøl · Diress Tsegaye (iD) - Kjetil Flydal · Jonathan E. Colman
}

Received: 17 August 2020/ Accepted: 18 May 2021/Published online: 31 May 2021

(C) The Author(s) 2021

\begin{abstract}
Context Within Rangifer ranges, many studies focus on expanding infrastructure and human activity negatively influencing habitat use. Little documentation exists on how disturbances act in synergy (i.e. cumulative effects), nor methods to test such effects.

Objectives (1) Investigate how cumulative disturbance at different distances affects reindeer habitat use and (2) at what disturbance levels and distances loss of habitat functionality occurs.

Methods Disturbance intensity levels for trails and infrastructure were based on expected amount of human activity, on a scale from 1 to 6 . To test cumulative disturbance, we adapted the multi-grain method and summed-up disturbance intensity levels within "disturbance distance intervals" (0-0.25, $0.25-1,1-2 \mathrm{~km}$, etc. instead of $0-0.25,0-1,0-2 \mathrm{~km}$,
\end{abstract}

Supplementary Information The online version contains supplementary material available at https://doi.org/10.1007/ s10980-021-01263-1.

S. Eftestøl · D. Tsegaye $(\bowtie) \cdot$ K. Flydal · J. E. Colman Department of Biosciences, Centre for Ecological \& Evolutionary Synthesis (CEES), University of Oslo, Blindern, P.O. Box 1066, 0316 Oslo, Norway e-mail: d.t.alemu@ibv.uio.no

S. Eftest $\varnothing 1$ - D. Tsegaye · J. E. Colman Faculty of Environmental Sciences and Natural Resource Management, Norwegian University of Life Sciences, P.O. Box 5003, 1432 Ås, Norway etc.), and tested reindeers' avoidance using GPS data for 2011-2018.

Results We found decreased habitat use within $0.25 \mathrm{~km}$ with increasing cumulative disturbance for snow free and winter seasons. For spring, a similar effect occurred up to $1 \mathrm{~km}$. Reductions in use in areas with highest cumulative disturbance within these zones were between 92 and 98\%. Strongest avoidance during spring supports previous studies. Comparatively, the multi-grain approach showed negative effects up to $3 \mathrm{~km}$.

Conclusions Our approach provides novel results and precisely estimates where cumulative effects actually occur. Reindeer in our study tolerate low intensities of human disturbance, while further increase in disturbance intensity reduces habitat functionality. We suggest clustering future human developments within areas of high disturbance, i.e. where functional habitat use is already lost or highly reduced. Our method can be used for other areas and species.

Keywords Habitat use $\cdot$ Avoidance $\cdot$ Cumulative effects · Disturbance intensity $\cdot$ Habitat loss $\cdot$ Rangifer tarandus 


\section{Introduction}

Cumulative anthropogenic disturbance may affect home ranges and habitat functionality for wildlife (Theobald et al. 1997; Shackelford et al. 2018), possibly displacing the animals from important areas. Intensified human development in the northern hemisphere is a concern for future management of reindeer and caribou (Rangifer tarandus), a species known to avoid disturbances at relatively large spatial scales (Schaefer 2003; Hebblewhite and Fortin 2017; Plante et al. 2018). Thus, understanding the interactions of multiple disturbance types across large temporal and spatial scales is important for predicting how future developments may impact Rangifer populations (Polfus et al. 2011; Polfus and Krausman 2012), and many other wildlife populations.

Studies define cumulative effects differently based on concepts, classification, direction and utility (Duinker et al. 2013). Cumulative effects may occur when the joint effects of features in close proximity are greater or less than the influence of either of the features alone, indicating synergistic effects in space and time that are more than the sum of their parts (Ross and McGee 2006; Houle et al. 2010). Some (e.g. Brismar 2004) mainly emphasize cause-effect relationships that involve multiple root causes. A composite definition based on several authors is provided by Scherer (2011): "Cumulative effects are the net effect that a resource experiences from the combined influences of multiple management practices or influences often in combination with natural disturbance regimes distributed through space or time, or both". In another perspective, Harriman and Noble (2008) view cumulative environmental effects as "effects of an additive, interactive, synergistic, or irregular (surprise) nature, caused by individually minor, but collectively significant actions that accumulate over time and space". Although there is a growing literature regarding the concept and importance of cumulative effects as a component of the land use decisions for wildlife habitats, quantifying cumulative effects remains a challenge (Theobald et al. 1997; Gunn and Noble 2011).

There is a combined spatial and temporal aspect of "cumulative effects". Both disturbance intensity and animal vulnerability for disturbances vary over space and time, and the spatial and temporal distribution of disturbances may affect habitat use of populations.
Among planning and reindeer management authorities, a relevant issue is whether existing and future infrastructure and human activities should be clustered together in order to avoid negative effects in presently undisturbed areas (Theobald et al. 1997). Conversely, it can be argued that by clustering infrastructure in certain areas, some reindeer populations may be more severely affected than others. Some also argue that thresholds may exist, where a severe decrease in habitat use appears at certain levels of increased human disturbances (Groffman et al. 2006). Such thresholds could occur as a consequence of habitats being overly disturbed or destroyed at certain levels of human infrastructure (Frair et al. 2008), but also from severe disturbance effects of seasonal human activities, like number of snow-kiters within an area (Colman et al. 2012) or hikers along a trail (Strand et al. 2013). On the other hand, reindeer may also habituate to strong disturbance levels and/or the least vulnerable individuals (typically males or semi-domesticated reindeer in general) could be able to utilize pastures despite increased disturbance levels, in both time and space (Reimers and Colman 2006). This could be especially relevant for certain periods like winter, when alternative pastures could be limited and the animals' motivation might increase towards utilizing a "disturbed" area. Also, during summer, insect harassment may be an important factor overriding human disturbances (Skarin et al. 2004). Thus, behaviour reactions change over time, at least to a certain degree, and additional knowledge on cumulative effects over time and for different distance intervals is pertinent.

Within Rangifer ranges, effects of expanding infrastructure and increased human activity negatively influence the functionality of habitats, such as calving areas, spring and winter pastures, and other limiting habitats specific for a population (Panzacchi et al. 2015). In recent years, many studies have addressed cumulative effects of human disturbances on Rangifer habitat, but the approaches used vary considerably and most seem to have difficulties in quantifying cumulative effects in relation to the conceptual definitions described above. Most studies define cumulative effects as the total disturbance level within the entire seasonal range of a population. In this perspective, several independent, non-interactive disturbances are studied, and the "cumulative effects" are presented as the cumulative habitat loss for the focus population 
based on the independent effects from each infrastructure studied (e.g. Johnson et al. 2005, 2015; Polfus et al. 2011; Panzacchi et al. 2013; Plante et al. 2018). However, while acknowledging the importance of such cumulative effects studies, there is little documentation on how disturbances act in synergy within smaller areas.

In this study, we introduce a method to evaluate cumulative disturbances for human activities and infrastructure correlated in space. Together with other habitat variables, we used resource selection function (RSF) models as a simplified method to examine how animal responses change with increasing disturbance intensities across different spatial scales and seasons within the Ildgruben reindeer district in Nordland, Norway. Our approach of merging layers of spatially correlated disturbances provides an understanding of cumulative effects, but without separating effects of each disturbance type or including interactions. The Ildgruben reindeer population range is affected by the population centre of Mo i Rana, numerous smaller settlements, main roads, dirt roads, railway, cabins, tourist resorts, power lines, hydropower, mining, seasonal outdoor activities and more. Part of the range is affected by several disturbance factors, while other sections by one or just a few disturbance factors. A major part of the range is not affected by infrastructure or trails, but may still have hunters, occasional alpine skiers, etc. We defined the disturbance level of different types of infrastructure or trails based on the intensity of associated human activity (e.g. major roads had a higher disturbance level than minor roads). We then calculated the cumulative disturbance level for different distance intervals for all GPS- and random locations and investigated how this affected habitat functionality; i.e. habitat use within defined seasons (for details see methods). Due to the densities and distribution of human infrastructure and activities within Ildgruben, the study area is ideal for testing effects of a continuous range of disturbance intensity levels within defined distance intervals and seasons, from no disturbance to very high cumulative disturbance levels.

Our aim was to investigate how increased cumulative disturbance at different distance intervals affects reindeer habitat use and at what disturbance level it leads to loss of habitat functionality. Using reindeer as a case, we aim to provide new insights into organizing available data and testing synergetic, cumulative effects of infrastructure and anthropogenic activities on wildlife populations within an overlapping temporal and spatial context.

\section{Study area and methods}

\section{Study area}

Ildgruben reindeer district is located in Nordland county, Norway. The population is restricted to approx. $2700 \mathrm{~km}^{2}$, encompassing year-round seasonal reindeer habitats (Fig. 1) for a winter population varying between 888 and 1458 reindeer over the last 20 years. Throughout our study period, the winter population was between 888 and 1014, giving a winter density of approx. 3 animals $/ \mathrm{km}^{2}$ (Reindriftsforvaltningen 2008; Landbruksdirektoratet 2018). Most human activity and infrastructure is concentrated along the coast, but with some heavily developed areas in central parts, including roads, tourist resorts and cabin areas, trails and large hydropower developments. Other areas are less influenced, but may include isolated cabins, tourist cabins, hiking trails, hydropower development, minor roads and power lines. Consequently, there are little remaining areas $>3 \mathrm{~km}$ away from infrastructure within the Ildgruben reindeer population's range (approx. 9\%, Fig. 2), a common scenario for many reindeer districts and some wild reindeer populations in Norway. Seasonal, functional habitats in Ildgruben overlap and vary among years based on snow conditions, plant phenology, predator's occurrence, human disturbances and herding strategies. During the last 10-15 winter seasons, large proportions of the population are fed within or close to the main reindeer enclosure nearby the herders' houses, centrally located in the district. The winter feeding has been necessary due to the loss of winter pastures within Sweden from 2005 (Tom Lifjell, 'pers. comm.').

From the highly developed coastal areas in the west, elevation increases sharply up to mountain plateaus between 600 and1100 masl, with deeper forested valleys and larger hydropower development mostly below 600 masl. Southern parts of the district include alpine ridges up to 1900 masl (Fig. 1). 


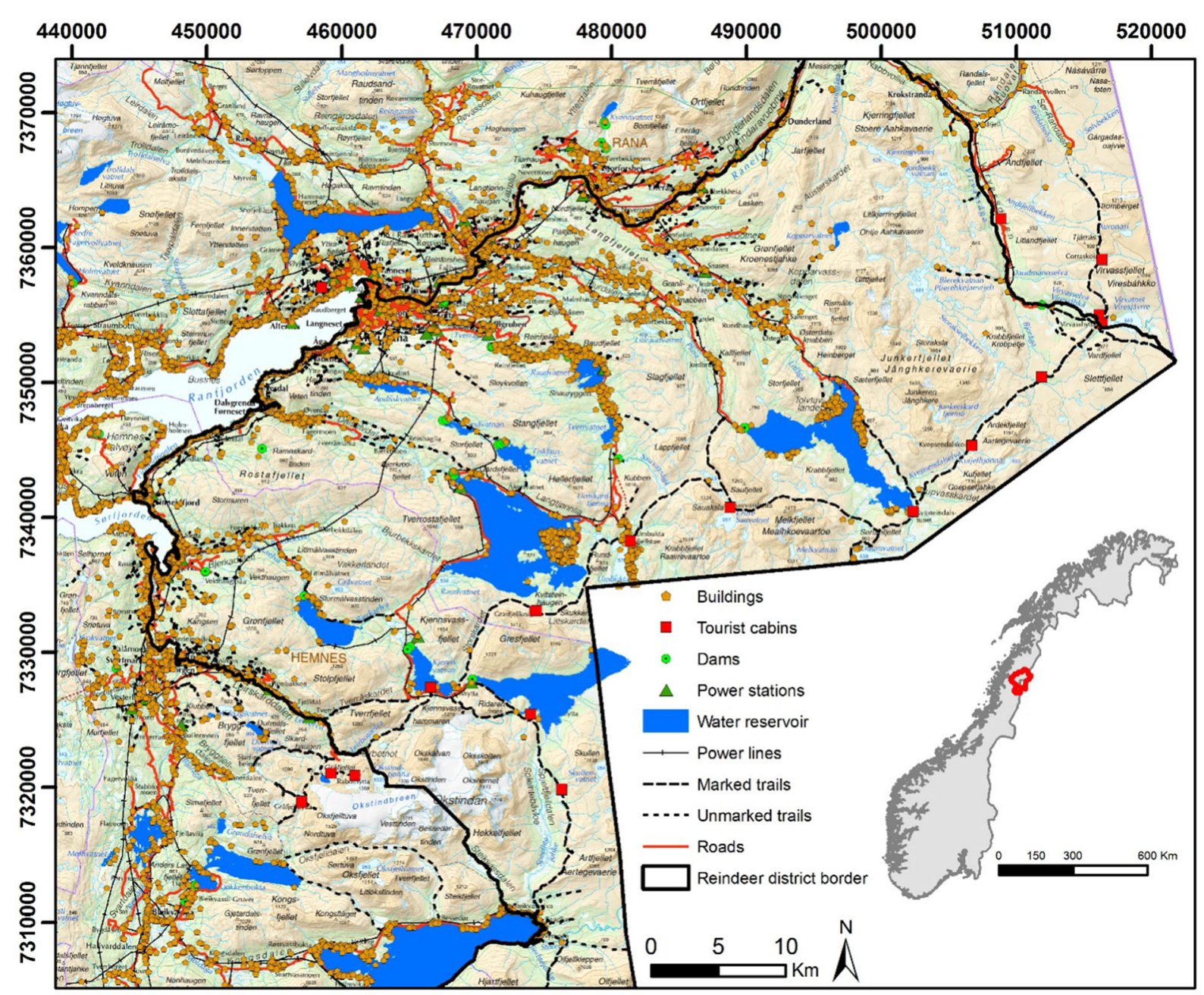

Fig. 1 Study area map showing the location of infrastructure and trails, Ildgruben reindeer district in Nordland, Norway

Reindeer data

In total, 624,908 GPS positions were gathered from 44 GPS-collared reindeer females, representing 240 individual reindeer-years over eight years (16 March 2011 to 21 June 2018). GPS fixes below two-hour intervals and fixes located outside the reindeer district borders were removed. We also removed all data when the animals were within fenced pens, were fed or otherwise handled by herders (i.e. during herding and gathering of animals, and one day before and after herding/gathering), or when herders forgot to turn the GPS-collars off after removing them from animals. We also removed some rare GPS locations within larger lakes, because they were considered not available. In some cases, GPS-locations were missing due to GPS-malfunctions; when only 4 or less consecutive GPS-locations were missing, we extrapolated the coordinates based on the time interval and the coordinates before/after. In total, $39 \%$ of the GPSdata was removed as erroneous positions based on the above listed criteria (most of which was within or close to the main pens during winter while being fed). Thus, the total number of GPS-positions included in our analysis was 383382 .

\section{Seasons}

We divided the study period into seven seasons based on reindeer ecology and habitat functionality (such as calving and rutting, plant phenology, insect harassment and snow conditions), herding practices 

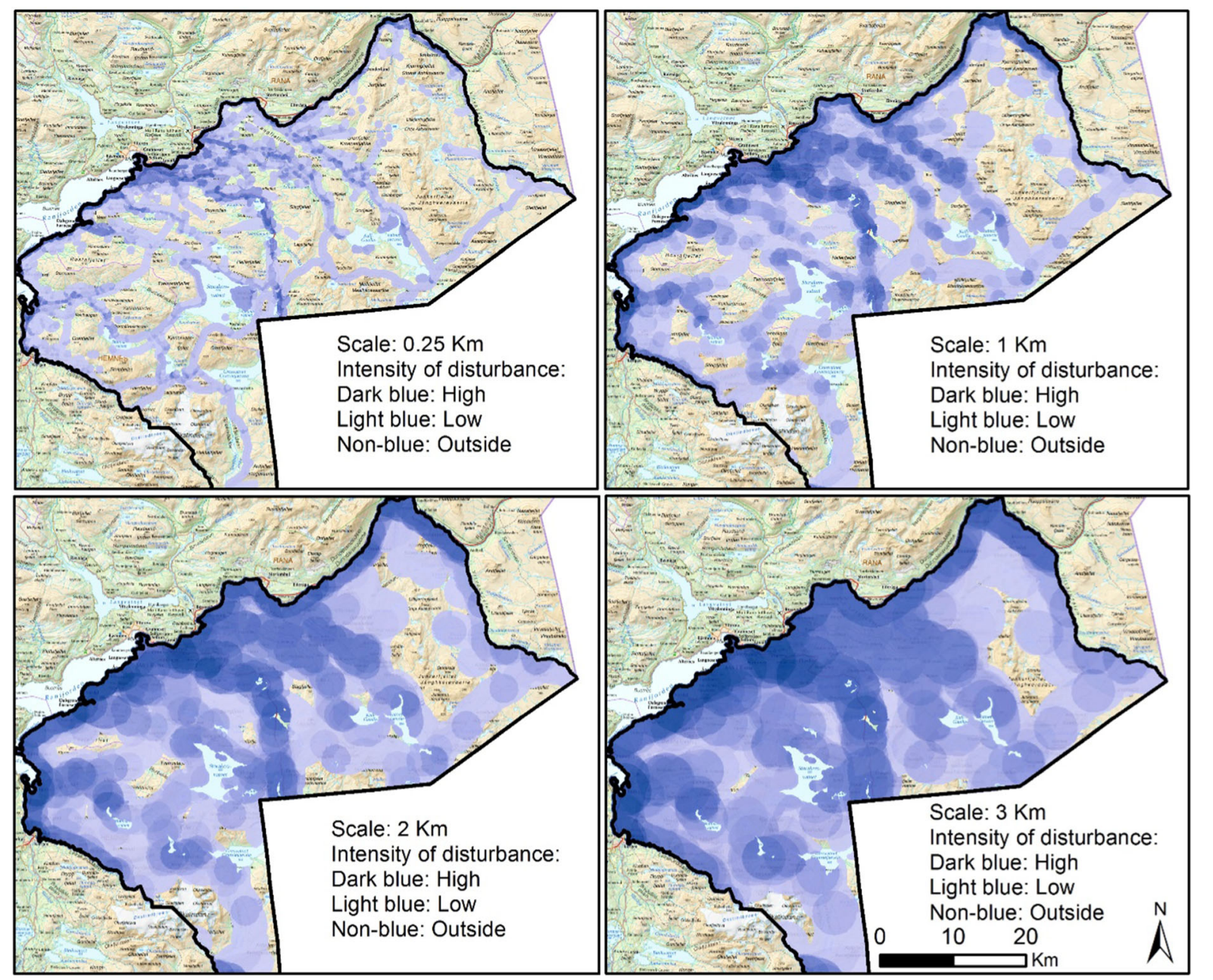

Fig. 2 Cumulative disturbance across different scales. The proportion of the area sizes outside each scale were approx. 76, 45, 21 and $9 \%$ at $0.25,1,2$, and $3 \mathrm{~km}$, respectively

(gatherings, herding between seasonal pastures, and more) (Eftestøl et al. 2016) and partly also due to the general levels of human outdoor activities (Table 1). The seasons include early winter (1 November-31 January), mid-winter (1 February-15 March), late winter (16 March-30 April), calving (1 May-15 June), post-calving (16 June-until 1 day before gathering), summer (1 day after gathering period until 31 August) and autumn (1 September-30 October). The end of the post-calving period varied each year depending on the gathering period (i.e. the earliest was 1 July and the latest was 24 July). Similarly, the start of the summer season varied each year (the earliest was 9 July and the latest was 31 July). Due to the complexity of having seven seasons when interacting seasons with other variables, we merged the seven seasons into three broader seasons for the final data analysis: "Winter" (early, mid- and late winter), "Spring" (calving and post-calving) and "Snow free" (summer and autumn).

Infrastructure disturbance intensity and scale

To test how increased levels of human activities and infrastructure within an area act in synergy and affect reindeer habitat use, i.e. cumulative effect (e.g. Ross and McGee 2006; Harriman and Noble 2008; Houle et al. 2010), we categorized the disturbance from each infrastructure and trail into different disturbance intensity levels. Based on previous findings in avoidance studies related to Rangifer (see review by Flydal 
Table 1 Disturbance levels for different infrastructure and trails

\begin{tabular}{|c|c|c|}
\hline Infrastructure type or trail & Disturbance levels & $\begin{array}{l}\text { Expected human } \\
\text { activity }\end{array}$ \\
\hline Ski trails (only in winter) & 1 Off season, 3 when prepared & Negligible to low \\
\hline Tourist cabins & $\begin{array}{l}1 \text { (Early winter), } 2 \text { (Calving and Post-calving), } 3 \text { (Mid-winter), and } 4 \text { (Late } \\
\text { winter, Summer and Autumn) }\end{array}$ & $\begin{array}{l}\text { Negligible to } \\
\text { medium }\end{array}$ \\
\hline Power stations & 1 (All seasons) & Negligible \\
\hline Power lines & 1 (All seasons) & Negligible \\
\hline Hydropower & 1 (All seasons) & Negligible \\
\hline Tourist trails (marked) & $\begin{array}{l}1 \text { (Early winter, Calving and Post-calving), } 2 \text { (Mid-winter), and } 3 \text { (Late winter, } \\
\text { Summer and Autumn) }\end{array}$ & Negligible to low \\
\hline Other trails (less used) & $\begin{array}{l}1 \text { (Early winter, Mid-winter, Calving and Post-calving), and } 2 \text { (Late winter, } \\
\text { Summer and Autumn) }\end{array}$ & $\begin{array}{l}\text { Negligible to very } \\
\text { low }\end{array}$ \\
\hline Major roads & 5 (All seasons) & High \\
\hline Minor roads & $\begin{array}{l}1 \text { (Early winter), } 2 \text { (Mid-winter, Calving and Post-calving), and } 3 \text { (Late winter, } \\
\text { Summer and Autumn) }\end{array}$ & Negligible to low \\
\hline Settlements & 6 (All seasons) & Very high \\
\hline $\begin{array}{l}\text { Housing, groups of } 1-2 \\
\text { buildings* }\end{array}$ & 3 (All seasons) & Low \\
\hline $\begin{array}{l}\text { Housing, groups of } 3-5 \\
\text { buildings* }\end{array}$ & 4 (All seasons) & Medium \\
\hline $\begin{array}{l}\text { Housing, groups of } 6-20 \\
\text { buildings* }\end{array}$ & 5 (All seasons) & High \\
\hline $\begin{array}{l}\text { Housing, groups of } \\
20+\text { buildings* }\end{array}$ & 6 (All seasons) & Very high \\
\hline $\begin{array}{l}\text { Cabins, groups of } 1-2 \\
\text { buildings* }\end{array}$ & $\begin{array}{l}1 \text { (Early winter, Calving and Post-calving), and } 2 \text { (Mid-winter, Late winter, } \\
\text { Summer and Autumn) }\end{array}$ & $\begin{array}{l}\text { Negligible to very } \\
\text { low }\end{array}$ \\
\hline $\begin{array}{l}\text { Cabins, groups of } 3-5 \\
\text { buildings* }\end{array}$ & $\begin{array}{l}1 \text { (Early winter, Calving and Post-calving), and } 3 \text { Mid-winter, Late winter, } \\
\text { Summer and Autumn) }\end{array}$ & Negligible to Low \\
\hline Cabins, 6-20 buildings* & $\begin{array}{l}2 \text { (Early winter, Calving and Post-calving), and } 4 \text { Mid-winter, Late winter, } \\
\text { Summer and Autumn) }\end{array}$ & $\begin{array}{l}\text { Very low to } \\
\text { medium }\end{array}$ \\
\hline Cabins, $20-50$ buildings* & $\begin{array}{l}3 \text { (Early winter, Calving and Post-calving), and } 5 \text { Mid-winter, Late winter, } \\
\text { Summer and Autumn) }\end{array}$ & Low to high \\
\hline $\begin{array}{l}\text { Cabins, groups of } \\
50+\text { buildings* }\end{array}$ & $\begin{array}{l}4 \text { (Early winter, Calving and Post-calving), and } 6 \text { Mid-winter, Late winter, } \\
\text { Summer and Autumn) }\end{array}$ & $\begin{array}{l}\text { Medium to very } \\
\text { high }\end{array}$ \\
\hline
\end{tabular}

The disturbance level was defined based on expected levels of human activity, and disturbance effects reported in previous studies (see review by Flydal et al. 2019) and also information from herders and tourist management authorities

*Defined as group if distance between buildings is $<500$

et al. 2019), we concluded that six levels, ranging from 1 (negligible to low disturbance) to 6 (very high disturbance), differentiated sufficiently between expected effects from different infrastructures (for details see Table 1). The infrastructure types are grouped into 6 levels with expected increase in disturbance effect, and not reflecting quantitative differences (i.e. does not mean that the highest level is 6 times stronger than the lowest). We assigned the lowest disturbance intensity levels for non-human use infrastructure (e.g. power lines and hydropower dams) and increasing levels for high human use infrastructure (e.g. settlements, major roads, cabin areas etc.). Many recent avoidance studies focus on several different types of anthropogenic disturbances, and most often these studies conclude with stronger negative effects of disturbances/infrastructure that typically generate higher levels of human activity. For example, Plante et al. (2018) found strongest negative effects around settlements, while no effects 
of power lines. Polfus et al. (2011) found stronger negative effects of high use roads than low use roads. Johnson et al. (2005) found strongest effects of minor and major developments, while effects were weaker/ non-existent for exploration sites and outfitter camps. Panzacchi et al. (2013) found strong negative effects for roads and tourist cabins, but no effects of private cabins, dams and power lines. Anttonen et al. (2011) likewise found strongest effects of population centers relative to buildings and main roads, while the effects of forest roads were negligible. Skarin et al. (2018) also found negative effects of two wind farms with associated human activity up to several $\mathrm{km}$, but no effects of power lines. Due to larger differences in methodology, population genetics, level of domestication, predator densities, actual amount of human activity levels along the infrastructure in question, the animals experience with humans (e.g. hunting vs nohunting populations/areas), size of alternative areas and animal motivation, we have only considered results within studies (not between studies) as the basis for defining the disturbance intensity levels.

Moreover, avoidance studies of reindeer that study different phases of the same infrastructure conclude with strongest negative effects for the phase or season that generate the most human activity and weaker/ negligible effects for the phase/season with less human activity. For instance, late phase of mine developments vs. early phase of mine development (Plante et al. 2018), seasons with high vs. low human use for mines and cabins (Polfus et al. 2011), after vs. before road upgrades (Leblond et al. 2013; Wilson et al. 2016), construction vs. operational phase of power lines (Eftestøl et al. 2016). Also, Strand et al. (2015) found stronger negative effects of hiking trails in periods when they were in heavy use by humans. Based on this, we differentiated the disturbance intensity levels between seasons and classified infrastructure mostly used in connection with outdoor activities (i.e. minor dirt roads, private cabins, tourist cabins and trails) with lower disturbance intensity levels during seasons with less outdoor activities, i.e. early winter, calving and post-calving (see Table 1 for details). Reduced outdoor activities during these seasons are reported for both hiking (Gundersen et al. 2019) and skiing (Lesmerises et al. 2018). Furthermore, local reindeer herders (Tom Lifjell, 'pers. comm.') and tourist authorities (Robert Bjugn, 'pers. comm.') confirmed such differences depending on season.

Similar to the multi-grain method (Laforge et al. 2015), we defined six radii up to $5 \mathrm{~km}$ around all real GPS- and random locations (i.e. within $0-0.25,0-1$, $0-2,0-3,0-4,0-5 \mathrm{~km})$. Since spatial mapping indicated that there was insufficient data for areas outside the intervals at larger scales, we limited our analyses to include only the first four distance intervals (i.e. including areas up to $3 \mathrm{~km}$ away from all locations, see Online Resource 1: Table S1). For each location for each radius and season, we defined the "cumulative disturbance" as the sum of "disturbance intensity" levels for all infrastructures and trails within that radii (for details see Table 1). If there are two independent ski trails, or two independent cabins within a radius, they are both accounted for. Every location that did not have any infrastructure or trail within a specific radius was considered to have a cumulative disturbance of zero for that radii. However, in one important aspect our method differs from the multi-grain method. Specifically, for each successive radius, we only included locations that had a cumulative disturbance of zero from the preceding radius, e.g. for the radius from $0-1 \mathrm{~km}$, we only included real GPS and random locations that had a cumulative disturbance of zero within $0-0.25 \mathrm{~km}$. This means that for each radius analysed, all the disturbances were between $0-0.25,0.25-1,1-2$ and 2-3 km away from each location, respectively (see Online Resource 1: Table S1). This was done because the multi-grain method "combines" distance zones with increasing distance, and thus, does not provide precise information on exactly where cumulative effects occur. By doing this, we could investigate how cumulative effects affected the animals at different "disturbance distance intervals".

\section{Habitat variables}

To control for landscape features and grazing conditions, we extracted elevation, slope and aspect for each data point from topographic data provided by Norge Digitalt (pixel size $25 \times 25 \mathrm{~m}$ ) and 25 vegetation types provided by NORUT (Landsat TM/ETM + , pixel size $30 \times 30 \mathrm{~m}$, available at https://norut.no/) for each data point using ArcGIS version 10.4.1. Aspect was converted into numerical values, ranging from 0 (north facing) to 180 (south facing). We 
classified the 25 vegetation/habitat types into five main groups (details are given in Online Resource 1: Table S2) based on different seasonal functionality as grazing habitat (Gaare and Skogland 1975).

\section{Data analysis}

We generated regular points (100 by $100 \mathrm{~m}$ ) within the entire district. From these regular points, we then randomly extracted an equal number of points to the real GPS-locations within the annual seasonal kernel home range to define available area. This was done with a replacement command, i.e. the same regular point could be extracted several times. We did not include random locations in larger lakes because these areas were considered not available. Similar to Plante et al. (2018), we used kernel home range to identify both habitat used and therefore areas 'available' within seasonal ranges. Kernel density estimation (KDE) is widely used in home-range estimation since its introduction into the field by Worton (1989).

We evaluated the summed up intensity of human disturbances (i.e. cumulative disturbance) on reindeer habitat use using resource selection functions (RSF; Manly et al. 2002) by fitting logistic regression with generalized linear mixed model in $\mathrm{R}$ (Bates et al. 2014). We analysed separately for each disturbance distance interval (i.e. within $0.25,0.25-1,1-2$, 2-3 km) for a better understanding of how reindeer respond to increasing cumulative disturbance when disturbances are at close distance, or further away. In some cases, we may find a positive or no effect at intermediate distance intervals and negative at further distances. Consequently, we performed additional analyses by merging such type of intervals (e.g. we analysed $0.25-2 \mathrm{~km}$ if no effect at $0.25-1 \mathrm{~km}$ and furthermore, $0.25-3 \mathrm{~km}$ if no effect at $0.25-2 \mathrm{~km}$ ) to better understand such results, as well as investigate cumulative effects more thoroughly (results are given in Online Resource 2: Fig S1). Prior to all the above analyses, we also analysed using a multi-grain with different radii (i.e. $0-0.25,0-1,0-2,0-3 \mathrm{~km}$ ) approach following Laforge et al. (2015) to understand general context (results are given in Online Resource 2: Fig S2) and to compare results of our new approach with Laforge et al. (2015).

The response variable was binomial (used/available). The explanatory variables included cumulative disturbance, season (categorical with 3 levels), habitat types (categorical with 5 levels), elevation, slope, and aspect. Season was interacted with all other explanatory variables. We also added a squared term (both simple terms and interactions) for continuous variables (cumulative disturbance, elevation, slope and aspect) since they showed a curvilinear trend. All variables were screened for collinearity using variance inflation factors (VIF; Zuur et al. 2009), with VIF $\geq 3.0$ as a threshold for removing a variable. The VIF did not indicate any apparent multi-collinearity $(\mathrm{VIF}<3)$ among habitat variables. We included individual reindeer year as a random factor to account for individual yearly variations (Zuur et al. 2009). We used Akaike's information criterion (AIC-values) to identify the most parsimonious model (see Online Resource 1; Table S3). To illustrate the results from the RSF models, we estimated relative probability of selection to show effects of the cumulative disturbance.

All analyses were done in $\mathrm{R}$ version 3.5.1 ( $\mathrm{R}$ Core Team 2019).

\section{Results}

We found strong negative effects of increased cumulative disturbance from infrastructure and trails in all seasons at the smaller distance intervals, with less or no effect at larger intervals (Fig. 3; see also Table 2, and Online Resource 1: Table S4). With increasing cumulative disturbance, we found a sharp decrease in reindeer habitat use within $0.25 \mathrm{~km}$ in all seasons. Within the seasonal home range, the level of relative use decreased between 92 and 98\% (depending on seasons) for the highest cumulative disturbance within this interval. We also found a strong decreasing effect within $0.25-1 \mathrm{~km}$ during spring when the disturbance level was above approx. 7, with a decrease in use of $92 \%$ for the highest disturbance levels, while other seasons showed no negative effects outside $0.25 \mathrm{~km}$ (Fig. 3). We did not find effects outside $1 \mathrm{~km}$ for any season, weaker but significant positive trends with increasing cumulative disturbance during winter and spring within the 1-2 km distance interval, neither did we find any clear differences between the base line probabilities for each distance interval. When merging distance intervals that did not show negative effects independently, the results did not change (see Online Resource 2: Fig S1). However, when using the multi- 


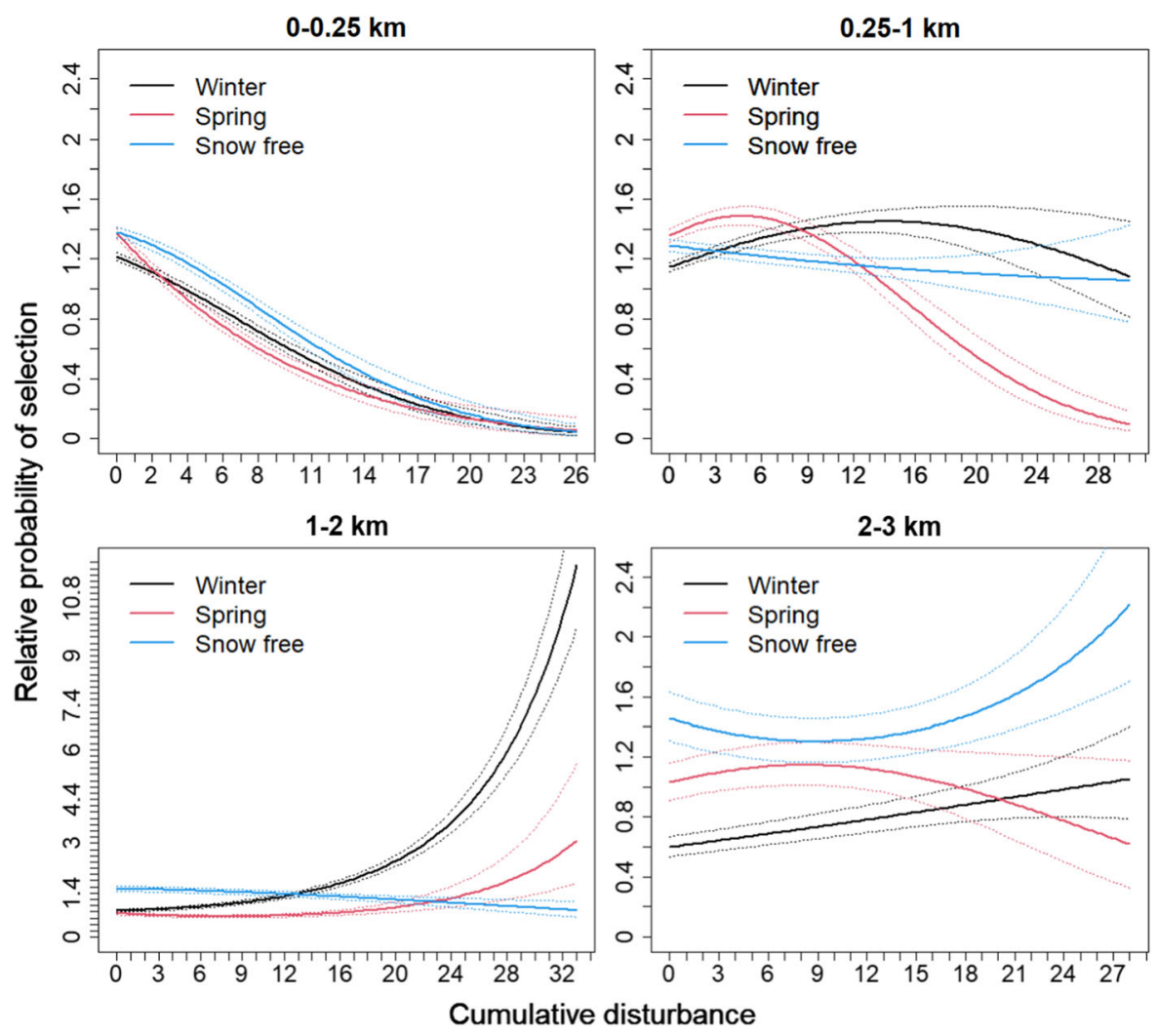

Fig. 3 Relative probability $( \pm 95 \% \mathrm{CI})$ of reindeer resource selection in relation to cumulative disturbance (i.e. sum of disturbance intensity levels) from the top predictive models within four disturbance distance intervals $(0-0.25,0.25-1,1-2$, and $2-3 \mathrm{~km}$ ) for reindeer resource selection (RSF) during winter, spring and snow-free seasons from 2011 to 2018 in the

grain approach, negative effects occurred up to $3 \mathrm{~km}$ during spring and snow-free seasons as long as cumulative disturbance becomes high enough. Such analyses did not change results for winter season (see Online Resource 1: Table S5; Online Resource 2: Fig S2). The highest disturbance levels within the seasonal home range varied between 13 and 26 (within the $0-0.25 \mathrm{~km}$ distance interval), and was lowest during spring (Fig. 3). Population home range varied between seasons (Fig. 4).

Reindeer selected lower elevation during spring and winter, and higher elevation during the snow free season. They selected lower slopes in all seasons for all distance intervals. Reindeer selected south facing aspect in all seasons, except selected north facing during the snow free season within the $1 \mathrm{~km}$ distance interval (Table 2). Reindeer selection for habitat types varied highly between seasons, but did not vary much
Ildgruben reindeer district in Nordland, Norway. The relative probability of selection for the cumulative disturbance predictor variable were calculated while keeping the other continuous predictor variables constant (at their mean values). The cumulative disturbance relates to the number of disturbances present within each distance interval, not the density

among the distance intervals (see Table 2; Online Resource 1: Table S4).

\section{Discussion}

Our study design, predefining disturbance intensity levels for different types of trails and infrastructure in different seasons, allowed us to investigate cumulative disturbance effects on habitat functionality of reindeer at different distance intervals and different seasons. Furthermore, adapting the multi-grain method (Laforge et al. 2015) to a disturbance distance interval approach, i.e. only including real GPS- and random locations with a cumulative disturbance of zero from preceding radii when analysing the cumulative effects, provided more precise results for where cumulative effects occurred. As expected, we found the strongest 


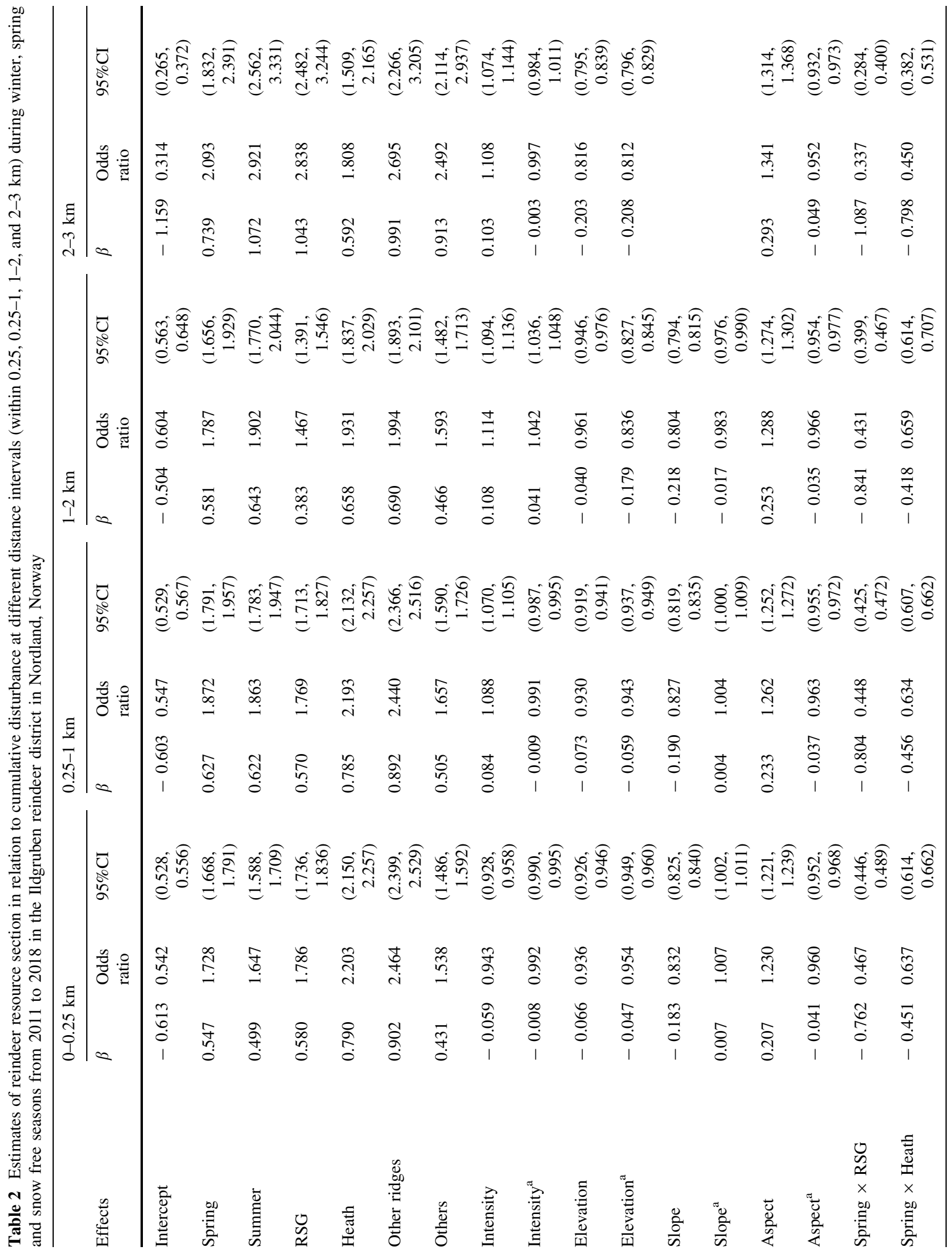




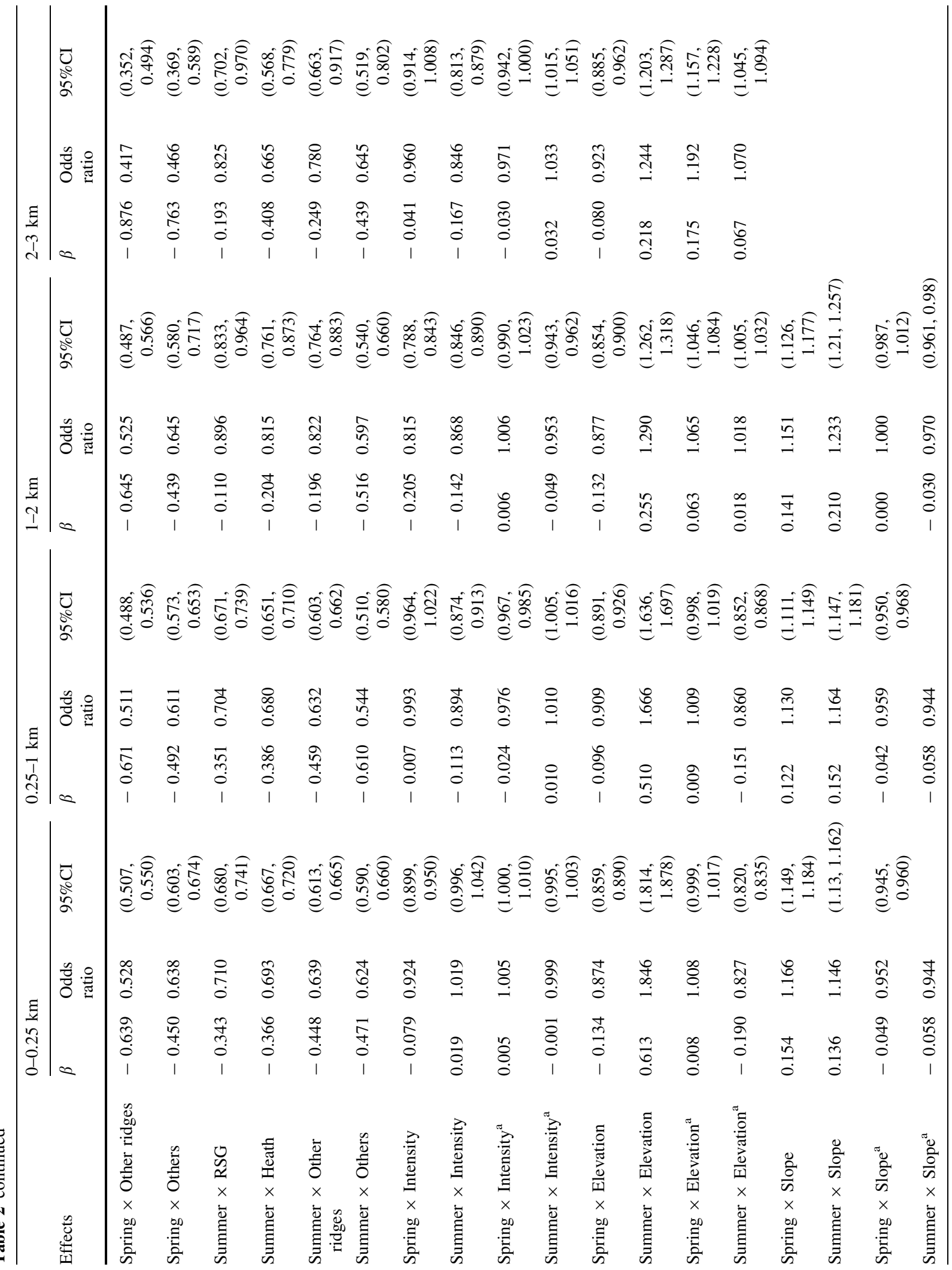




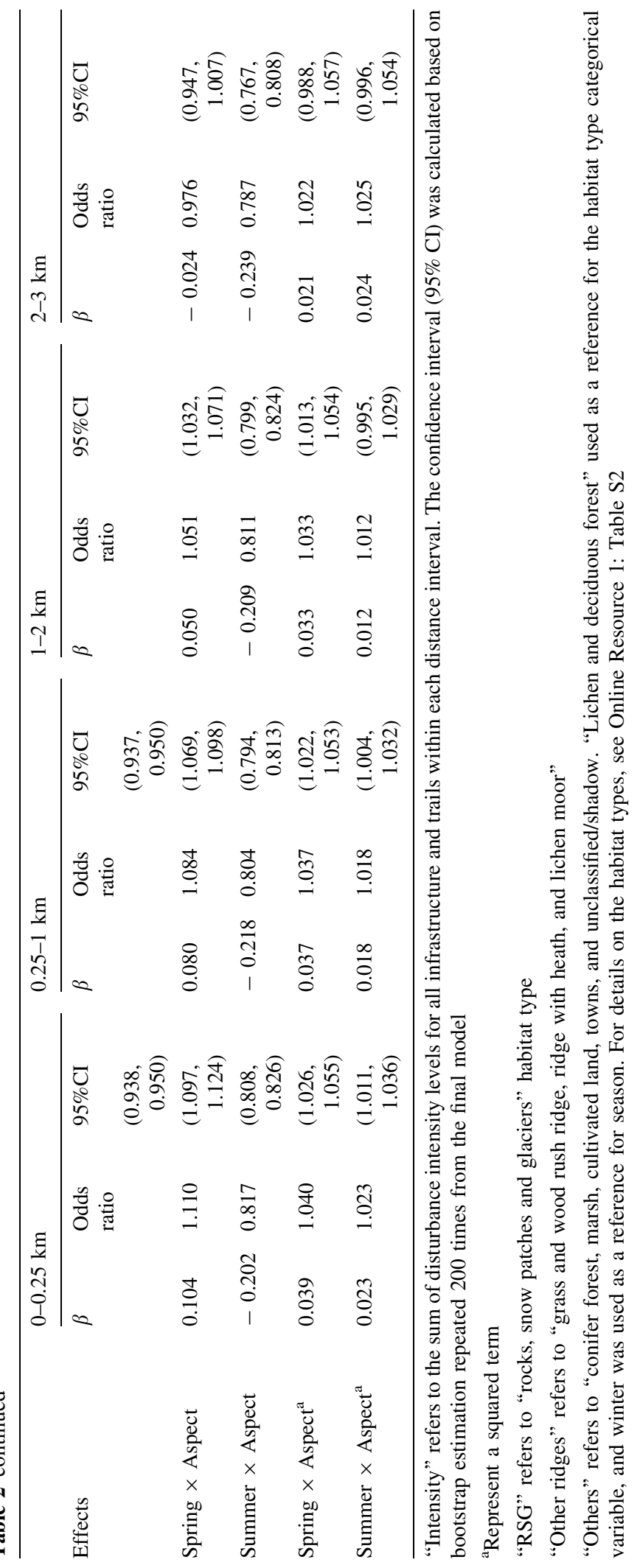



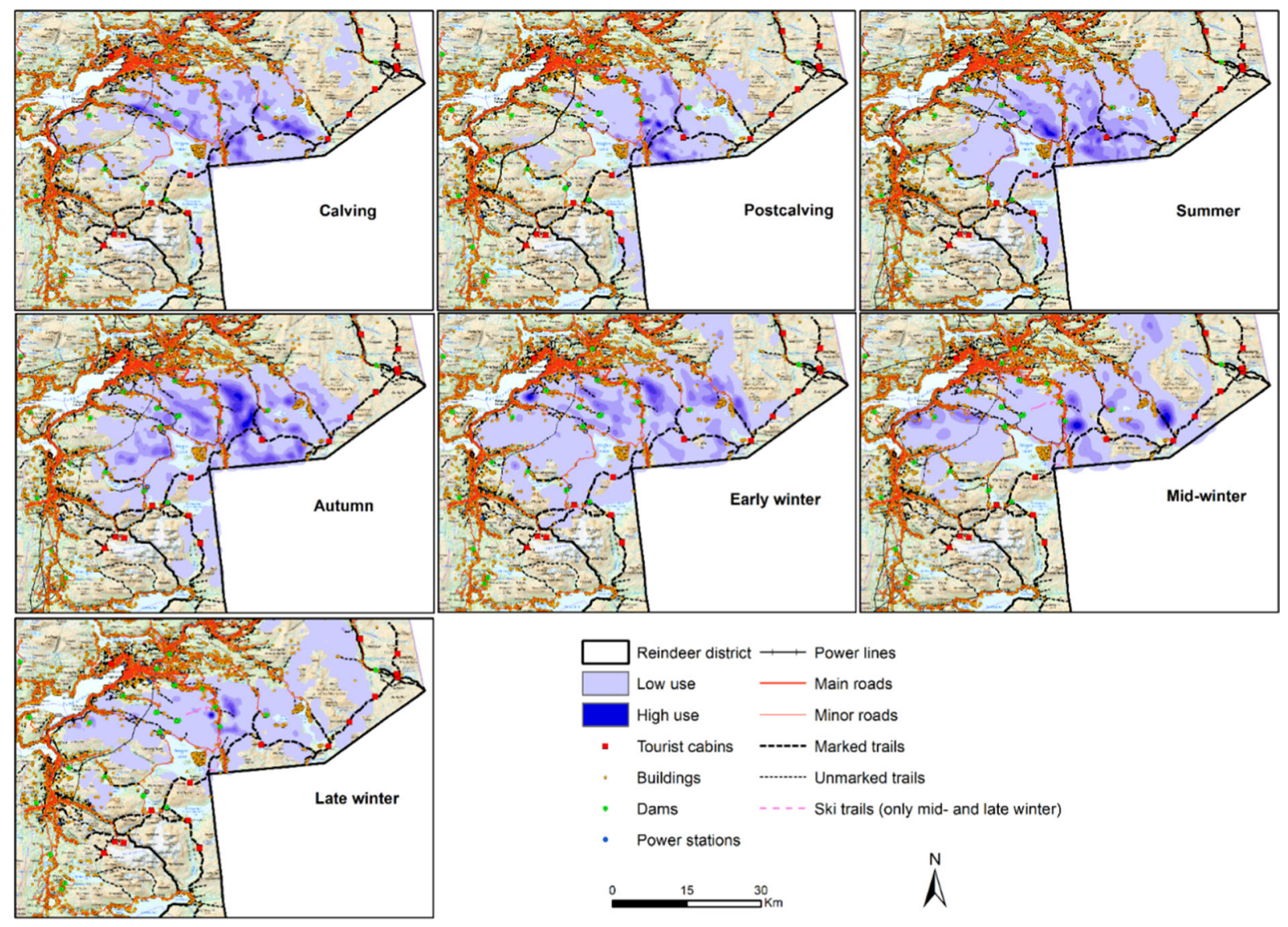

Fig. 4 Seasonal population home range (Kernel 99\%) in the Ildgruben reindeer district in Nordland, Norway (see also Fig. 2 for intensity of disturbance levels)

negative effects on reindeer habitat use with high cumulative disturbance within short distances (i.e. $0-0.25 \mathrm{~km}$ for all seasons, and $0-1 \mathrm{~km}$ for spring). The negative relationship between reindeer habitat use and cumulative disturbance was strong for all seasons, but strongest during spring, when reindeer are known to be vulnerable towards disturbances due to vulnerability of calves (Tveraa et al. 2014). Contrary to previous studies on wild reindeer (e.g. Nellemann et al. 2010) and caribou (e.g. Boulanger et al. 2012; Johnson et al. 2015; Plante et al. 2018), we did not find negative effects of human disturbances at distances $>1 \mathrm{~km}$.

The main trends in our study showed a decrease in reindeer habitat use with increased cumulative disturbance. This was as expected and lend support to numerous studies (Johnson et al. 2005; Polfus et al. 2011; Panzacchi et al. 2013; Plante et al. 2018). Rangifer behavior has evolved as a trade-off between optimal grazing and predator/parasite avoidance (Frid and Dill 2002; Stankowich 2008). Avoiding harmless stimuli within the environment would be maladaptive, and thus, it is likely to find weak/no effects of stationary objects without human presence (e.g. closed cabins, power lines, hydropower developments) on reindeer behavior. This might explain why we found negligible effects of cumulative disturbance levels $<$ 3 , even for the closest scale of our study. In general, we found a steeper decrease in area use when disturbance intensity increased. During spring for distance interval $0.25-1 \mathrm{~km}$, negative effects did not occur before the cumulative disturbance level was above approx. level 7. The latter result may indicate a disturbance threshold with few effects on habitat functionality, provided that the total disturbance stays below a certain levels, yet we did not find a clear abrupt change of ecological functionality as described by Groffman et al. (2006). The interactions between 
disturbance stimuli and other controllable and uncontrollable habitat factors are complex (Flydal et al. 2019). In relation to this, our results contrasts findings in a road network study on elk (Frair et al. 2008), where the disturbance threshold seemed to exist at almost zero road densities, i.e. the strongest negative change of effect was when the road densities were lowest. It also contrasts with some large-scaled avoidance studies on reindeer that found the strongest rate of change on habitat use when the cumulative human disturbance was low (e.g. Nellemann et al. 2010). Probably, influence zones, disturbance thresholds and the specific relationship between effect and change in cumulative disturbance are highly different depending on type of infrastructure, species, population and interacting environmental factors, like predators. This supports general evolutionary biology theory, i.e. reactions towards various stimuli are affected by both genetics and environmental factors (Dobzhansky 1950).

Approx. $45 \%$ and $9 \%$ of the entire reindeer district is more than 1 and $3 \mathrm{~km}$, respectively, away from human infrastructures or activities, suggesting that lack of alternative undisturbed areas may also have influenced our results. High cumulative disturbances were mostly located along the coast or in deep valleys, with large elevation differences between disturbance source and preferred reindeer habitat, particularly during winter, probably also affecting reindeer responses. Furthermore, within our study site, densities of lynx (Lynx lynx) and wolverine (Gulo gulo) are high (https://www.miljodirektoratet.no/ ansvarsomrader/naturoppsyn, Tom Lifjell pers. comm.), and the reindeer district report yearly mortality rates on calves $>30 \%$ due to predation (https:// www.landbruksdirektoratet.no/). Clearly, indirect effects of predation (Frair et al. 2008) could affect avoidance responses in cervids. Since semi-domesticated reindeer are not hunted, and show weaker response to human disturbance than hunted wild reindeer in Scandinavia (Baskin and Hjältén 2001; Reimers et al. 2009, 2012), they may find predator refuge in areas with relatively high levels of human disturbance (Hebblewhite and Merrill 2007). Reindeer herdsmen activities also likely leads to an adaptive behaviour towards human activity and infrastructure in general and/or override some of the negative effects from human developments. The above factors might partly explain why low cumulative human disturbance had limited effect on reindeer habitat use in our study site, especially outside $0.25 \mathrm{~km}$. However, further research on human-predator-reindeer interactions is needed to reveal whether predator refuge, elevation differences or reindeer herder activities may override potential negative effects of low to medium human disturbance intensities before conclusions can be drawn on this.

Multivariate RSF models can show how separate infrastructure types affect habitat use at a landscape or home range level or scale within larger study areas (e.g. Panzacchi et al. 2013; Johnson et al. 2015; Plante et al. 2018; Skarin et al. 2018). However, distinguishing disturbance effects of one infrastructure from the other is challenging when there are many disturbance types present within smaller areas. Our analysis was based on a combined disturbance layer, and thus more able to show cumulative effects of the total disturbance level in smaller areas containing several spatially correlated disturbances. It may also assist in establishing thresholds at which the animals begin to avoid an area, partly or completely, because of cumulative effects. We found that our method with distance intervals provides a more precise understanding of cumulative effects of disturbances than the broader multi-grain approach used by Laforge et al. (2015). For example, looking at the results during spring for the multi-grain approach, the effects within $0-3 \mathrm{~km}$ are clearly explained by the disturbances within $0-1 \mathrm{~km}$, and those disturbances alone, when comparing these results with the results from our distance interval approach (See Online Resource 2; Fig S2). Depending on a species home range and vulnerability for disturbances, distance intervals and disturbance levels should be modified.

We found high use of areas with low to medium infrastructure disturbance levels, especially if these disturbances were further away than $0.25 \mathrm{~km}$ (i.e. the areas within 0.25 did not have any disturbances). However, fright, flight and increased movement rates due to human encounters could still be an issue within such areas (Reimers et al. 2006, 2009; Strand et al. 2013), negatively influencing the animals' energy budgets, even if it does not induce seasonal avoidance (Reimers et al. 2014). Furthermore, our specific categorization may not be accurate enough to uncover weaker effects from "real" low and medium disturbance level infrastructure. More research on such consequences must be done before concluding that 
low cumulative disturbance has no or negligible effects on habitat functionality. Also, we have not investigated barrier effects directly that may reduce connectivity between areas even if it does not lead to avoidance per se. Therefore, in line with pre-cautionary principle, best practice is likely to cluster future human developments within areas of already existing high cumulative disturbance, i.e. where functional habitat use is already lost or highly reduced, rather than spreading new activities and infrastructure within larger areas with no or low levels of disturbance.

\section{Conclusions}

This study introduces new methodology and an improved understanding of how cumulative effects can be organized and tested in a combined spatial and temporal context applicable for other species and study areas in future studies. Our results imply that increasing probability of human presence and the human-reindeer predator-prey relationship is the driving force behind seasonal avoidance from cumulative anthropogenic stimuli. The results show that reindeer may tolerate low cumulative disturbance, while a further increase in disturbance may be critical. In theory, this means that for some reindeer populations, some disturbances in pristine areas and in certain seasons can occur before it leads to clear avoidance. However, it is important to emphasize that with relatively intensive reindeer herder strategies, limited alternative areas (in our case, further away than $3 \mathrm{~km}$ ) and high predator density, the relatively low avoidance found in Ildgruben is not directly transferable to other reindeer or caribou areas. Our main contribution is not the specific avoidance distances found for reindeer shown in this case study, but that negative effects from human activities and infrastructure on wildlife in general increases with increasing intensity of disturbance, and adds new insights to the existing literature.

Acknowledgements This work was supported by Statnett, Statskog, The Norwegian Water Resources and Energy Directorate, Fylkesmannan i Nordland, the Norwegian Research Council (NRC project 255635). We would like to thank reindeer herders, Tom Lifjell and Stig Lifjell, from the Ildgruben reindeer district for very meaningful cooperation, lending us their reindeer, providing important background information, and assisting with GPS tagging. We also like to thank Robert Bjugn, leader of "Polarsirkelen turlag" tourist association for information about general use of tourist cabins and trails throughout the year.

Funding Open access funding provided by University of Oslo (incl Oslo University Hospital).

Open Access This article is licensed under a Creative Commons Attribution 4.0 International License, which permits use, sharing, adaptation, distribution and reproduction in any medium or format, as long as you give appropriate credit to the original author(s) and the source, provide a link to the Creative Commons licence, and indicate if changes were made. The images or other third party material in this article are included in the article's Creative Commons licence, unless indicated otherwise in a credit line to the material. If material is not included in the article's Creative Commons licence and your intended use is not permitted by statutory regulation or exceeds the permitted use, you will need to obtain permission directly from the copyright holder. To view a copy of this licence, visit http://creativecommons.org/licenses/by/4.0/.

\section{References}

Anttonen M, Kumpula J, Colpaert A (2011) Range selection by semi-domesticated reindeer (Rangifer tarandus tarandus) in relation to infrastructure and human activity in the boreal forest environment, Northern Finland. Arctic 64:1-14

Baskin LM, Hjältén J (2001) Fright and flight behavior of reindeer. Alces 37:435-445

Bates D, Mächler M, Bolker BM, Walker S (2014 ) Fitting linear mixed-effects models using lme4. http://arxiv.org/pdf/ 1406.5823.pdf. Accessed 07 May 2019

Boulanger J, Poole KG, Gunn A, Wierzchowski J (2012) Estimating the zone of influence of industrial developments on wildlife: a migratory caribou Rangifer tarandus groenlandicus and diamond mine case study. Wildl Biol 18:164-179. https://doi.org/10.2981/11-045

Brismar A (2004) Attention to impact pathways in EISs of large dam projects. Environ Impact Asses Rev 24:59-87. https:// doi.org/10.1016/S0195-9255(03)00162-8

Colman JE, Lilleeng MS, Tsegaye D, Vigeland MD, Reimers E (2012) Responses of wild reindeer (Rangifer tarandus tarandus) when provoked by a snow-kiter or skier: a model approach. Appl Anim Behav Sci 142:82-89. https://doi. org/10.1016/j.applanim.2012.08.009

Dobzhansky T (1950) Heredity, environment, and evolution. Science 11:161-166

Duinker PN, Burbidge EL, Boardley SR, Greig LA (2013) Scientific dimensions of cumulative effects assessment: toward improvements in guidance for practice. Environ Rev 21:40-52. https://doi.org/10.1139/er-2012-0035

Eftest $\varnothing 1$ S, Tsegaye D, Flydal K, Colman JE (2016) From high voltage $(300 \mathrm{kV})$ to higher voltage $(420 \mathrm{kV})$ power lines: reindeer avoid construction activities. Polar Biol 39:689-699. https://doi.org/10.1007/s00300-015-1825-6

Flydal K, Tsegaye D, Eftestøl S, Reimers E, Colman JE (2019) Rangifer within areas of human influence: understanding 
effects in relation to spatiotemporal scales. Polar Biol 42:1-16

Frair JL, Merrill EH, Beyer HL, Morales JM (2008) Thresholds in landscape connectivity and mortality risks in response to growing road networks. J Appl Ecol 45:1504-1513. https:// doi.org/10.1111/j.1365-2664.2008.01526.x

Frid A, Dill LM (2002) Human-caused disturbance stimuli as a form of predation risk. Conserv Ecol 6:11

Gaare E, Skogland T (1975) Wild reindeer food habits and range use at Hardangervidda. In: Wielgolaski FE, Kallio P, Kauri $\mathrm{H}$, Ostbye E, Rosswall $\mathrm{T}$ (eds) Fennoscandian tundra ecosystems: ccological studies (analysis and synthesis), vol 17. Springer, Berlin, pp 195-205

Groffman PM, Baron JS, Tea B (2006) Ecological thresholds: the key to successful environmental management or an important concept with no practical application? Ecosystems 9:1-13

Gundersen V, Vistad OI, Panzacchi M, Strand O, van Moorter B (2019) Large-scale segregation of tourists and wild reindeer in three Norwegian national parks: management implications. Tourism Manage 75:22-33. https://doi.org/ 10.1016/j.tourman.2019.04.017

Gunn J, Noble BF (2011) Conceptual and methodological challenges to integrating SEA and cumulative effects assessment. Environ Impact Asses Rev 31:154-160. https://doi.org/10.1016/j.eiar.2009.12.003

Harriman JAE, Noble BF (2008) Characterizing regional approaches to project and cumulative effects assessment in Canada. JEAPM 10:25-50. https://doi.org/10.1142/ S1464333208002944

Hebblewhite M, Fortin D (2017) Canada fails to protect its caribou. Science 358:730-730. https://doi.org/10.1126/ science.aar 2464

Hebblewhite M, Merrill EH (2007) Multiscale wolf predation risk for elk: does migration reduce risk? Oecologia 152:377-387. https://doi.org/10.1007/s00442-007-0661-y

Houle M, Fortin D, Dussault C, Courtois R, Ouellet JP (2010) Cumulative effects of forestry on habitat use by gray wolf (Canis lupus) in the boreal forest. Landsc Ecol 25:419-433. https://doi.org/10.1007/s10980-009-9420-2

Johnson CJ, Boyce MS, Case RL, Cluff HD, Gau RJ, Gunn A, Mulders R (2005) Cumulative effects of human developments on arctic wildlife. Wildl Monogr 160:1-36

Johnson CJ, Ehlers LPW, Seip DR (2015) Witnessing extinction - cumulative impacts across landscapes and the future loss of an evolutionarily significant unit of woodland caribou in Canada. Biol Conserv 186:176-186. https://doi.org/10. 1016/j.biocon.2015.03.012

Laforge MP, Vander Wal E, Brook RK, Bayne EM, McLoughlin PD (2015) Process-focussed, multi-grain resource selection functions. Ecol Model 305:10-21. https://doi.org/10. 1016/j.ecolmodel.2015.03.003

Landbruksdirektoratet (2018) Ressursregnskap for reindriftsnæringen, for reindriftsåret 1. april 2017 - 31. mars 2018 (in Norwegian). Rapport nr. 30/2018.

Leblond M, Dussault C, Ouellet JP (2013) Avoidance of roads by large herbivores and its relation to disturbance intensity. J Zool 289:32-40. https://doi.org/10.1111/j.1469-7998. 2012.00959.x

Lesmerises F, Dery F, Johnson CJ, St-Laurent MH (2018) Spatiotemporal response of mountain caribou to the intensity of backcountry skiing. Biol Conserv 217:149-156. https://doi.org/10.1016/j.biocon.2017.10. 030

Manly BF, McDonald L, Thomas D, McDonald TL, Erickson WP (2002) Resource selection by animals: statistical design and analysis for field studies. Kluwer Academic Publishers, Boston

Nellemann C, Vistnes I, Jordhøy P, Støen OG, Kaltenborn BP, Hanssen F, Helgesen R (2010) Effects of recreational cabins, trails and their removal for restoration of reindeer winter ranges. Restor Ecol 18:873-881. https://doi.org/10. 1111/j.1526-100X.2009.00517.x

Panzacchi M, Van Moorter B, Jordhøy P, Strand O (2013) Learning from the past to predict the future: using archaeological findings and GPS data to quantify reindeer sensitivity to anthropogenic disturbance in Norway. Landsc Ecol 28:847-859. https://doi.org/10.1007/s10980012-9793-5

Panzacchi M, Van Moorter B, Strand O, Loe LE, Reimers E (2015) Searching for the fundamental niche using individual-based habitat selection modelling across populations. Ecography 38:659-669. https://doi.org/10.1111/ ecog.01075

Plante S, Dussault C, Richard JH, Cote SD (2018) Human disturbance effects and cumulative habitat loss in endangered migratory caribou. Biol Conserv 224:129-143. https://doi. org/10.1016/j.biocon.2018.05.022

Polfus JL, Hebblewhite M, Heinemeyer K (2011) Identifying indirect habitat loss and avoidance of human infrastructure by northern mountain woodland caribou. Biol Conserv 144:2637-2646. https://doi.org/10.1016/j.biocon.2011.07. 023

Polfus JL, Krausman PR (2012) Impacts of residential development on ungulates in the Rocky Mountain West. Wildl Soc B 36:647-657. https://doi.org/10.1002/wsb.185

R Core Team (2019) R: a language and environment for statistical computing. R Foundation for Statistical Computing. https://www.R-project.org/. Accessed 31 August 2020

Reimers E, Colman JE (2006) Reindeer and caribou (Rangifer tarandus) response to human activity. Rangifer 26:55-71

Reimers E, Loe LE, Eftestøl S, Colman JE, Dahle B (2009) Effects of hunting on response behaviors of wild reindeer. J Wildl Manage 73:844-851. https://doi.org/10.2193/ 2008-133

Reimers E, Miller FL, Eftestol S, Colman JE, Dahle B (2006) Flight by feral reindeer Rangifer tarandus tarandus in response to a directly approaching human on foot or on skis. Wildl Biol 12:403-413

Reimers E, Røed KH, Colman JE (2012) Persistence of vigilance and flight response behaviour in wild reindeer with varying domestic ancestry. J Evolut Biol 25:1543-1554. https://doi.org/10.1111/j.1420-9101.2012.02538.x

Reimers E, Tsegaye D, Colman JE, Eftestol S (2014) Activity patterns in reindeer with domestic vs. wild ancestry. Appl Anim Behav Sci 150:74-84. https://doi.org/10.1016/j. applanim.2013.10.010

Reindriftsforvaltningen (2008) Ressursregnskap for reindriftsnæringen, for reindriftsåret 1 April 2006-31 March 2007 (in Norwegian)

Ross H, McGee TK (2006) Conceptual frameworks for SIA revisited: a cumulative effects study on lead contamination 
and economic change. Impact Assess Project Apprais 24:139-149. https://doi.org/10.3152/14715460678176 5273

Schaefer JA (2003) Long-term range recession and the persistence of caribou in the taiga. Conserv Biol 17:1435-1439.

Scherer R (2011) Cumulative effects: a primer for watershed managers. Streamline Watershed Manage Bull 14:14-20

Shackelford N, Standish RJ, Ripple W, Starzomski BM (2018) Threats to biodiversity from cumulative human impacts in one of North America's last wildlife frontiers. Conserv Biol 32:672-684. https://doi.org/10.1111/cobi.13036

Skarin A, Danell Ö, Bergström R, Moen J (2004) Insect avoidance may override human disturbances in reindeer habitat selection. Rangifer 24:95-103

Skarin A, Sandström P, Alam M (2018) Out of sight of wind turbines-reindeer response to wind farms in operation. Ecol Evol 00:1-14. https://doi.org/10.1002/ece3.4476

Stankowich T (2008) Ungulate flight responses to human disturbance: a review and meta-analysis. Biol Conserv 141:2159-2173. https://doi.org/10.1016/j.biocon.2008.06. 026

Strand O, Flemsæter F, Gundersen V, Rønningen K (2013) Horisont Snøhetta-NINA (in Norwegian). Temahefte $51: 99$

Strand O, Gundersen V, Jordhøy P, Andersen R, Nerhoel I, Panzacchi M, Van Moorter B (2015) Villrein og ferdsel i
Rondane: Sluttrapport fra GPS-merkeprosjektet 20092014.-NINA Rapport 1013. 170s ('In Norwegian').

Theobald DM, Miller JR, Hobbs NT (1997) Estimating the cumulative effects of development on wildlife habitat. Landsc Urban Plan 39:25-36. https://doi.org/10.1016/ S0169-2046(97)00041-8

Tveraa T, Stien A, Broseth H, Yoccoz NG (2014) The role of predation and food limitation on claims for compensation, reindeer demography and population dynamics. J Appl Ecol 51:1264-1272. https://doi.org/10.1111/1365-2664. 12322

Wilson RR, Parrett LS, Joly K, Dau JR (2016) Effects of roads on individual caribou movements during migration. Biol Conserv 195:2-8. https://doi.org/10.1016/j.biocon.2015. 12.035

Worton BJ (1989) Kernel methods for estimating the utilization distribution in home-range studies. Ecology 70:164-168. https://doi.org/10.2307/1938423

Zuur AF, Ieno EN, Walker NJ, Saveliev AA, Smith GM (2009) Mixed effects models and extensions in ecology with R. Springer, New York

Publisher's Note Springer Nature remains neutral with regard to jurisdictional claims in published maps and institutional affiliations. 